\title{
À RODA DOS DELÍ́RIOS DE MORTE DE MACHADO E FLAUBERT: MEMóRIAS PÓSTUMAS DE BRÁS CUBAS E UN CEUR SIMPLE
}

\author{
por Luciana Antonini Schoeps ${ }^{1}$
}

\begin{abstract}
RESUMO: O objetivo deste artigo é trazer algumas conclusões a partir da comparação temática dos delírios de morte presentes em Memórias póstumas de Brás Cubas de Machado de Assis e Un cour simple de Gustave Flaubert. Tal processo comparativo abriu nosso campo de análise, propiciando reflexões que problematizaram as relações entre literatura e psicanálise e o caráter mimético da descrição.
\end{abstract}

PalaVRas-ChaVe: Gustave Flaubert, Machado de Assis, Literatura e Psicanálise, Descrição.

ABSTRACT: The aim of this article is to compare some episodes of delirium occuring during the main characters' death as depicted in Machado de Assis' The Posthumous Memories of Bras Cubas and Flaubert's A simple soul. The comparative process lead to a reflection on the relations between literature and psychoanalysis and on the mimetic attributes of description.

KEYWORDS: Gustave Flaubert, Machado de Assis, Literature and psychoanalysis, Description.

RESUME: Le but de cet article est de présenter quelques conclusions à partir de la comparaison thématique des délires de mort présents dans Memórias póstumas de Brás Cubas de Machado de Assis et Un cœur simple de Gustave Flaubert. Ce processus comparatif a élargi notre champ d'analyse, ce qui a permis des réflexions qui ont rendu problématiques les rapports entre la littérature et la psychanalyse et l'aspect mimétique de la description.

MOTS CLES: Gustave Flaubert, Machado de Assis, Littérature et Psychanalyse, Description.

\section{INTRODUÇÃO}

O presente artigo, pretendendo comparar os delírios de morte presentes na obra flaubertiana e machadiana, seguirá num percurso de análise crítica que almeja ser inconcluso. Dessa forma, adentraremos um universo de análise que, como o feixe discursivo descrito por Foucault em L'archéologie du savoir (1969), operou não uma convergência, mas uma difusão, apontando para várias questões que se implicam numa rede de relações aqui estabelecida. Assim sendo, tentaremos aqui recuperar algumas dessas questões.

\section{COMPARAR Flaubert E MACHAdo a PARTIR do tema: UMA INCURSÃo NA PSiCANÁliSe}

Alucinações de morte: gozo místico e delírio laico. Félicité, personagem do conto Un cour simple de Flaubert, morre em seu quarto, invadido pelo incenso de uma procissão, tendo a visão mística de seu papagaio, associado durante todo o conto ao Espírito Santo. Brás

\footnotetext{
${ }^{1}$ Luciana Antonini Schoeps é bacharel em Letras (Português/Francês) pela Universidade de São Paulo, tendo realizado, com a orientação da Prof ${ }^{a}$ Dra. Verónica Galíndez Jorge e financiamento da Fapesp, pesquisa de Iniciação Científica intitulada "Alucinações de morte na obra de Flaubert e Machado: o gozo místico e o delírio laico", pesquisa da qual o presente artigo é resultado. Membro do Grupo de Estudos Literatura Loucura Escritura, publicou o artigo "Alucinações de morte na obra de Flaubert e Machado: o gozo místico e o delírio laico" (In: CIRILLO, J. et GRANDO, A. (orgs.). Processo de criação e interações: a crítica genética em debate nas artes, ensino e literatura. $1^{\text {a }}$ ed. Belo Horizonte: C/Arte, 2008, vol. 2.). Iniciou, neste ano, Mestrado em Língua e Literatura Francesa na USP, estudando os processos de criação em Flaubert e Machado.
} 
Cubas, personagem de Memórias póstumas de Brás Cubas de Machado, é arrebatado por um hipopótamo e levado ao encontro de Pandora, que lhe revelaria o último dos séculos, visão que termina malograda. Duas alucinações distintas, que se afastam quanto ao tratamento temático dado ao delírio, se seguirmos o que nos diz Lacan acerca do assunto.

Lacan, em seu Seminário XX (1975), aborda a existência de um gozo místico, no qual o sujeito entraria em consonância com o Outro, objeto de nosso incessante desejo. O sujeito, dessa forma, deve ser encarado como um sujeito desejante que, impulsionado pela busca do primeiro e impossível objeto de desejo - a mãe ${ }^{2}$-, busca, ao longo de sua vida, vários outros que não o completam, pois são objetos parciais. No gozo místico, experiência pela qual passaram místicos religiosos tais como Santa Tereza d'Ávila e San Juan de la Cruz, o sujeito atingiria não um objeto parcial (outro), mas um objeto total (Outro), num gozo no qual, para Lacan, a face de Deus estaria suportada ${ }^{3}$. Esse gozo, mais facilitado em mulheres, já que estas não estão presas ao gozo fálico, podendo gozar desse gozo suplementar ${ }^{4}$, também pode ser observado em homens, tal como podemos depreender do famoso caso de paranóia que Freud analisou a partir do relato de memórias do próprio paciente, Schreber:

Uma outra vez ainda tive a sensação de estar sendo levado à beatitude; tive, então, sob mim, por assim dizer, nas alturas do céu, repousando sob uma abóbada azul, toda a Terra, um quadro de beleza e esplendor incomparáveis; para designar este quadro ouvi uma expressão que soa aproximadamente como: "Perspectiva de que Deus esteja Junto". (SCHREBER, 1903, p. 91)

Dessa forma, o gozo místico se configura primordialmente como uma experiência na qual o sujeito entra em contato com a transcendência. Assim sendo, apenas pelo breve resumo do enredo das cenas dos delírios aqui estudados, podemos dizer que Félicité atinge o gozo místico ao entrever o papagaio-Espírito Santo, enquanto que Brás Cubas não atinge a consonância com o Outro, ao não obter nenhuma visão reveladora e ao passar por um delírio marcado pela laicidade. No entanto, vale a pena olhar mais detidamente para os elementos presentes nas obras que nos permitem assim caracterizar os delírios, num olhar crítico que inclui as relações possíveis entre literatura e psicanálise.

No conto flaubertiano, a cena do delírio de morte da personagem aparece de forma entrecortada, num movimento que oscila entre a descrição da procissão que ocorre na cidade e a descrição da morte de Félicité dentro do quarto. Esse movimento pendular faz com que o curso da narrativa central - entendida como a narração da vida e da morte de uma personagem - seja desviado pela incursão da descrição de um espaço externo, o que atrasa o desfecho do conto. Nesse sentido, entrevemos aí uma importante característica da escritura flaubertiana, que inclui na narrativa momentos de ausência da ação, nos quais se inscreve uma descrição quase sempre empreendida sob o ponto de vista de uma personagem, tal como postula Jean Rousset em um artigo sobre o romance Madame Bovary: "il est dans le génie flaubertien de préférer à l'événement son reflet dans la

\footnotetext{
${ }^{2}$ Essa relação com o primeiro objeto de desejo, tendo por base a teoria psicanalítica, é brilhantemente descrita de forma sucinta por Philippe Willemart: "Freud tinha situado a origem do ser humano na fusão inicial com a mãe, que representa o máximo da incorporação "gozante", em que todos os poros da pele estão concernidos. A criança aconchegada no útero materno é o paradigma. A vida tenta reencontrar inconscientemente essa sensação primordial de todas as maneiras possíveis. A teoria psicanalítica conceituou essa busca como a procura do 'objeto perdido', perdido porque impossível de ser atingido. Irreal, portanto, e situado no registro do Imaginário, o gozo impossível é descrito por Lacan como a alucinação fundamental.” (1995, p.19)

3 "Esse gozo que se experimenta e do qual não se sabe nada, não é ele o que nos coloca na via da ex-sistência? E porque não interpretar uma face do Outro, a face de Deus, como suportada pelo gozo feminino?" (LACAN, 1975, p.103)

4 "Nem por isso deixa de acontecer que se ela [a mulher] está excluída pela natureza das coisas, é justamente pelo fato de que, por ser não-toda, ela tem, em relação ao que designa de gozo a função fálica, um gozo suplementar. (...) Há um gozo, já que nos atemos ao gozo, gozo do corpo, que é, se posso me exprimir assim (...) para além do Falo." (LACAN, 1975, p. 99-100)
} 
conscience, à la passion le rêve de la passion, de substituer à l'action l'absence de l'action et à toute présence un vide" (1962, p. 133) ${ }^{5}$. No entanto, se olharmos de perto a cena do delírio da personagem, veremos que a pretensa narração da morte de Félicité é também uma descrição. Esse movimento que vai de uma descrição a outra - do interior do quarto a seu exterior - é guiado pelo foco narrativo centrado nos sentidos da personagem, tal como podemos ver nos excertos que se seguem:

Des coups de cloche la réveillèrent; on sortait des vêpres. Le délire de Félicité tomba. En songeant à la procession, elle la voyait, comme si elle l'eût suivie.

Tous les enfants des écoles, les chantres et les pompiers marchaient sur les trottoirs tandis qu'au milieu de la rue s'avançaient premièrement: le suisse armé de sa hallebarde, le bedeau avec une grande croix, l'instituteur surveillant les gamins, la religieuse inquiète de ses petites filles (...)

Le murmure de la foule grossit, fut un moment très fort, s'éloignait.

Une fusillade ébranla les carreaux. C'étaient les postillons saluant l'ostensoir. Félicité roula ses prunelles, et elle dit, le moins bas qu'elle put :

- Est-il bien ? tourmentée du perroquet.

Son agonie commença. Un râle, de plus en plus précipité, lui soulevait les côtes. Des bouillons d'écume venaient aux coins de sa bouche, et tout son corps tremblait.

Bientôt, on distingua le ronflement des ophicléides, les voix claires des enfants, la voix profonde des hommes. Tout se taisait par intervalles, et le battement des pas, que des fleurs amortissaient, faisait le bruit d'un troupeau sur du gazon. (...)

Les fabriciens, les chantres, les enfants se rangèrent sur les trois côtés de la cour. Le prêtre gravit lentement les marches, et posa sur la dentelle son grand soleil d'or qui rayonnait. Tous s'agenouillèrent. Il se fit un grand silence. Et les encensoirs, allant en pleine volée, glissaient sur leurs chaînettes.

Une vapeur d'azur monta dans la chambre de Félicité. Elle avança les narines, en la humant avec une sensualité mystique; puis ferma les paupières. Ses lèvres souriaient. Les mouvements de son cour se ralentirent un à un, plus vagues chaque fois, plus doux, comme une fontaine s'épuise, comme un écho disparaît; et, quand elle exhala son dernier souffle, elle crut voir, dans les cieux entr'ouverts, un perroquet gigantesque, planant au-dessus de sa tête. (FLAUBERT, 1877, p.61-4, grifos nossos)

Como podemos ver, a descrição da procissão é guiada, no primeiro excerto, pelo olhar da personagem em delírio, que imagina o que estaria acontecendo no exterior de seu quarto (En songeant à la procession, elle la voyait, comme si elle l'eût suivie), fazendo com que a descrição do espaço externo seja subjetivada e incluída na alucinação da personagem.

Em seguida, no segundo excerto, a ênfase é dada na audição, uma vez que a descrição do espaço externo centra-se, primeiramente, nos sons da procissão (Le murmure de la foule grossit, Une fusillade ébranla les carreaux) para, em seguida, adentrar o quarto da personagem, descrevendo os ruídos da respiração da moribunda (Un râle, de plus en plus précipité, lui soulevait les côtes), e, finalmente, retornar aos sons do espaço externo (le ronflement des ophicléides, les voix claires des enfants, la voix profonde des hommes, le battement des pas, le bruit d'un troupeau sur du gazon), seguindo agora uma percepção auditiva com foco narrativo ambíguo, uma vez que a expressão francesa on distinga não nos permite definir quem é o sujeito dessa percepção, já que o pronome on é definido tanto por seu caráter de indefinição quanto por sua propriedade de substituir qualquer pessoa do

\footnotetext{
${ }^{5}$ Nesse sentido, esse vazio é o mesmo 'silêncio flaubertiano' de que nos fala Gérard Genette em 'Les silences de Flaubert" (1962).
} 
discurso $^{6}$. Dessa forma, essa percepção tanto pode ser da responsabilidade do narrador quanto da personagem, já que as fronteiras entre as duas instâncias foram relativizadas pelo pronome on, tal qual ocorre no discurso indireto livre. Assim sendo, se o foco desse trecho estiver na personagem, teríamos novamente uma descrição subjetivada.

Já no terceiro excerto, o que une os espaços externo e interno é um elemento que ativa o sentido do olfato, a saber, o incenso. Esse elemento místico, advindo de um espaço já ancorado na religiosidade - a procissão - adentra o quarto da personagem, na forma de um vapeur d'azur, que será respirado com uma sensualité mystique. Todo o retrato da personagem sugere aqui o gozo místico: a personagem, embevecida pelo incenso da procissão, sorri e vai morrendo aos poucos, conforme seu coração se cala. É interessante notar que, uma vez a procissão silenciada (Il se fit un grand silence), a personagem também vai silenciar-se, numa metáfora plena de sugestões sonoras: Les mouvements de son cour se ralentirent un à un, plus vagues chaque fois, plus doux, comme une fontaine s'épuise, comme un écho disparaît.

A comunhão com o religioso não é, portanto, apenas temática: ela é sugerida não apenas pelo conteúdo do delírio, mas também por toda a estrutura do trecho, que visa unir o espaço externo ao espaço interno da cena de morte, numa metonímia da consonância com o todo que se dará no desfecho do conto. Assim, ao final, coroando a morte da personagem, a visão do papagaio-Espírito Santo, que aparece nos céus entreabertos (dans les cieux entr'ouverts) fecha o conto e concretiza o gozo místico, através da consonância com o Outro.

No entanto, a presença marcante na estrutura da obra de um foco narrativo guiado pelos sentidos da personagem - o olhar e o ouvir - coloca em questão algo que é sistematizado pela psicanálise como promovedor de alucinações. Sobre esse assunto, Willemart, abordando as teorias freudiana e lacaniana, coloca as pulsões escópica (o olhar) e invocante (o ouvir) como propiciadoras de alucinações:

Nesse sentido, a pulsão escópica em Freud não somente reenvia ao Outro, mas atira-o numa pulsão total muito próxima dos místicos em que todo o ser está concernido e não somente o olhar. (1995, p. 58)

Lacan, distinguindo as quatro pulsões parciais, as pulsões oral, anal, escópica e invocante, diferencia nitidamente as duas últimas, que têm uma relação mais imediata com o grande Outro. $(1995$, p. 45)

Logo, justamente algo que é considerado como desencadeador de alucinações está presente de forma a estruturar o fio da narrativa do conto. Essa interseção entre literatura e psicanálise, algo anacrônica se levarmos em consideração a data de publicação do conto flaubertiano, época na qual a psicanálise ainda não era uma ciência plenamente constituída, mas um discurso de interesse em ascensão deve ser, pois, melhor compreendida, como veremos adiante, após observarmos o delírio machadiano.

Na obra de Machado de Assis, como sabemos, Brás Cubas, enquanto defunto-autor, resolve narrar seu delírio de morte, processo que passa por uma série de metamorfoses iniciais:

Primeiramente, tomei a figura de um barbeiro chinês, bojudo, destro, escanhoando um mandarim, que me pagava o trabalho com beliscões e confeitos: caprichos de mandarim.

Logo depois, senti-me transformado na Summa Theologica de S. Tomás, impressa num volume, e encadernada em marroquim, com fechos de prata e estampas; idéia esta que me deu ao corpo a mais completa imobilidade; e

\footnotetext{
6 “On désigne parfois une ou plusieurs personnes bien déterminées et prend ainsi, par syllepse de la personne, la valeur d'un des pronoms personnels je, tu, nous, vous, il(s), elle(s).” (GREVISSE, 1964, p. 502)
} 
ainda agora me lembra que, sendo as minhas mãos os fechos do livro, e cruzando-as eu sôbre o ventre, alguém as descruzava (Virgília de certo), porque a atitude lhe dava a imagem de um defunto.

Ùltimamente, restituído à forma humana, vi chegar um hipopótamo, que me arrebatou. (ASSIS, 1881, p. 120)

A presença de elementos do campo semântico da religiosidade, que poderiam apontar para a inserção do místico no delírio, como é o caso da Summa Theologica de São Tomás, servem, na realidade, para estabelecer um afastamento com relação a este, numa aproximação ao laico e ao burlesco, como nos sugere a profusão de elementos díspares, tais como um barbeiro chinês e a aparição de um hipopótamo. A incapacidade de transcendência, inclusive, já está posta na própria imagem construída pelo narrador, na qual a transformação em algo sagrado não permite a consonância com o Outro, mas gera uma sensação de desconforto e de imobilidade (idéia esta que me deu ao corpo a mais completa imobilidade) ${ }^{7}$. Assim sendo, o início do delírio já aponta para a impossibilidade da transcendência, negando de antemão o gozo místico.

Contudo, os elementos laicos e o afastamento com relação ao sagrado continuam a permear o delírio, que terá como figura central uma personagem da mitologia greco-romana, Pandora. O delírio, então, passará a se balizar na relação estabelecida entre a personagem Brás Cubas e Pandora, constituindo uma espécie de jogo dramático no qual Pandora apresentará a Cubas um desfilar de séculos, num espetáculo quase teatral:

Estupefacto, não disse nada, não cheguei sequer a soltar um grito; mas, ao cabo de algum tempo, que foi breve, perguntei quem era e como se chamava: curiosidade de delírio.

- Chama-me Natureza ou Pandora; sou tua mãe e tua inimiga.

(...)

- Não te assustes, disse ela, minha inimizade não mata; é sobretudo pela vida que se afirma. Vives: não quero outro flagelo.

- Vivo? perguntei eu, enterrando as unhas nas mãos, como para certificar-me da existência.

- Sim, verme, tu vives. Não receies perder êsse andrajo que é teu orgulho; provarás ainda, por algumas horas, o pão da dor e o vinho da miséria. Vives: agora mesmo que ensandeceste, vives; e se a tua consciência reouver um instante de sagacidade, tu dirás que queres viver.

(...)

- Creio; eu não sou sòmente a vida; sou também a morte, e tu estás prestes a devolver-me o que te emprestei. Grande lascivo, espera-te a voluptuosidade do nada.

(...)

- Porque já não preciso de ti. Não importa ao tempo o minuto que passa, mas o minuto que vem. O minuto que vem é forte, jucundo, supõe trazer em si a eternidade, e traz a morte, e perece como o outro, mas o tempo subsiste. Egoísmo, dizes tu? Sim, egoísmo, não tenho outra lei. Egoísmo,

\footnotetext{
${ }^{7}$ Tanto a disparidade dos elementos da metamorfose delirante da personagem quanto a imobilidade conferida pela transformação na Summa Theologica são notados por João Alexandre Barbosa, mas numa perspectiva que não seguimos aqui, vendo neles alusões críticas ao evolucionismo: “Ao entrar no capítulo VII propriamente, o leitor logo se defronta com o arbitrário das imagens oníricas: as relações entre 'um barbeiro chinês' e um mandarim, a Summa Theologica, de São Tomás, e um hipopótamo que serve de guia ao narrador. Mas arbitrário apenas superficialmente, como em todas as imagens oníricas: como não ver nas transformações do narrador, dada mesmo a sua arbitrariedade, uma alusão crítica à ciência evolucionista da época, com referência inclusive às sensações de vida na morte, como está na anotação sobre a consciência de imobilidade no episódio da Summa Theologica, em que subjaz o mesmerismo tão cultivado por um Edgard Poe, por exemplo?” (1989, p.111).
} 
conservação. A onça mata o novilho porque o raciocínio da onça é que ela deve viver, e se o novilho é tenro tanto melhor: eis o estatuto universal. Sobe e olha.

Isto dizendo, arrebatou-me ao alto de uma montanha. Inclinei os olhos a uma das vertentes, e contemplei, durante um tempo largo, ao longe, através de um nevoeiro, uma cousa única. Imagina tu, leitor, uma reducção dos séculos, e um desfilar de todos êles, as raças todas, todas as paixões, o tumulto dos impérios, a guerra dos apetites e dos ódios, a destruição recíproca dos sêres e das cousas. Tal era o espetáculo, acerbo e curioso espetáculo. (...)

Ao contemplar tanta calamidade, não pude reter um grito de angústia, que Natureza ou Pandora escutou sem protestar nem rir (...).

- Tens razão, disse eu, a cousa é divertida e vale a pena, - talvez monótona - mas vale a pena. (...) Vamos lá, Pandora, abre o ventre, e digereme; a cousa é divertida, mas digere-me.

A resposta foi compelir-me fortemente a olhar para baixo, e a ver os séculos que continuavam a passar, velozes e turbulentos, as gerações que se superpunham às gerações, umas tristes, como os Hebreus do captiveiro, outras alegres, como os devassos de Cômodo, e tôdas elas pontuais na sepultura. (...) Redobrei de atenção; fitei a vista; ia enfim ver o último, - o último!; mas então já a rapidez da marcha era tal, que escapava a tôda a compreensão; ao pé dela o relâmpago seria um século. Talvez por isso entraram os objectos a trocarem-se; uns cresceram, outros minguaram, outros perderam-se no ambiente; um nevoeiro cobriu tudo, - menos o hipopótamo que ali me trouxera, e que aliás começou a diminuir, a diminuir, a diminuir, até ficar do tamanho de um gato. (...) (ASSIS, 1881, p.121-5, grifos nossos)

Como podemos observar, o delírio de Cubas segue dentro de uma caracterização que busca negar os elementos da tradição cristã, num movimento de afastamento e rebaixamento de seus símbolos, tais como o pão e o vinho. O que simboliza o corpo e o sangue de Cristo é aqui colocado como pão da dor e vinho da miséria, numa revelação de Pandora que culmina numa visão niilista da transcendência, já que o que espera a personagem é a voluptuosidade do nada. Dessa forma, vemos que o delírio se afasta de uma transcendência possível ao negar símbolos próprios do religioso, num movimento de rebaixamento e distanciamento com relação a qualquer tradição estabelecida próprio do humor e da ironia machadianos ${ }^{8}$. Aqui não cabe mais uma cena na qual o incenso domina o quarto e a personagem embevecida pela visão de um papagaio-Espírito Santo; a personagem de Machado de Assis, ao contrário, é arrebatada por um hipopótamo, numa cena um tanto risível que culmina, no entanto, com uma visão aterradora, um espetáculo da calamidade dos séculos que lhe é dado a ver por Pandora, personagem mitológica responsável pelos males do mundo.

Todo o trecho do delírio é balizado por essa relação estabelecida entre as duas personagens, numa dialética na qual uma, Pandora, é encarregada de revelar o mistério dos séculos e a outra, Brás Cubas, é o destinatário dessa revelação. Essa revelação que estrutura a cena do delírio acontece a partir da contemplação de um espetáculo. Dessa forma, Brás Cubas se coloca numa posição de espectador, numa atitude predominantemente passiva e, pois, feminina de contemplação, o que nos remonta novamente à pulsão escópica. Percebemos não somente a intensa descrição do que a personagem vê, mas uma insistência enorme em verbos e expressões centrados no olhar: "Sobe e olha"; "Inclinei os olhos a uma das vertentes, e

\footnotetext{
${ }^{8} \mathrm{O}$ humor e a ironia da escrita de Machado de Assis, largamente estudados pela fortuna crítica machadiana, não foram explorados nesse estudo, uma vez que essa extensa questão nos afastaria de nosso foco principal de análise, a saber, o estudo da estrutura da cena do delírio e de sua relação com o discurso psicanalítico.
} 
contemplei"; "Ao contemplar tanta calamidade"; "A resposta foi compelir-me fortemente a olhar para baixo, e a ver os séculos que continuavam a passar"; "fitei a vista; ia enfim ver o último".

Ao contrário de Cubas, Pandora assume uma posição ativa e, portanto, masculina, pois além de ser a detentora de um segredo cobiçado pelos homens - a revelação do último século - ela coloca-se no lugar da lei, tanto ao dizer explicitamente não tenho outra lei, quanto ao dar ordens à personagem: Sobe e olha. Temos aí uma estrutura bastante peculiar, na qual entrevemos uma tríade: sujeito (Brás Cubas) - objeto (revelação dos séculos) - um terceiro (Pandora). É interessante observar que essa estrutura se assemelha ao que Lacan postula como sendo uma estrutura psíquica propiciadora da alucinação psicótica ${ }^{9}$. Sobre esse assunto, o psicanalista nos diz que esse tipo de alucinação seria gerado pela forclusão do Nome-do-Pai, lugar da Lei por excelência ${ }^{10}$, no simbólico do sujeito, ausência à qual se segue a invocação do Nome-do-Pai em oposição simbólica ao sujeito:

Mas como pode o Nome-do-pai ser chamado pelo sujeito no único lugar de onde poderia ter-lhe advindo e onde nunca esteve? Através de nada mais nada menos que um pai real, não forçosamente, em absoluto, o pai do sujeito, mas Um-pai.

É preciso ainda que esse Um-pai venha no lugar em que o sujeito não pôde chamá-lo antes. Basta que esse Um-pai se situe na posição terceira em alguma relação que tenha por base o par imaginário $a-a$, isto é, eu-objeto ou ideal-realidade. (1966, p. 584)

Poderíamos dizer que Pandora aparece no delírio de Cubas nessa posição de Nomedo-Pai, uma vez que ela é o elemento ativo da estrutura estabelecida, atuando no lugar da Lei por excelência. Além disso, ela coloca-se nessa posição de intermédio entre o sujeito e seu objeto de desejo, uma vez que ela é a mediadora entre Cubas e a visão do último século, tendo o poder tanto de dar a ver quanto de impedir a consonância sujeito-objeto. É interessante observar, no entanto, que essa consonância não é atingida, visto que a personagem não consegue ver a revelação do último século, acabando o delírio de forma disfórica, já que em vez da grande revelação anunciada, temos o retorno ao quarto da personagem, através da diminuição do hipopótamo, transformado em um gato.

O desfecho do delírio acaba por negar mais uma vez o gozo místico, já que aqui se coloca justamente a impossibilidade de qualquer visão reveladora dos mistérios da morte. Nessa forma que privilegia o anti-clímax, incluindo na narrativa inúmeras disforias, temos o que parece ser a tônica da escrita machadiana, marcada pelas negativas - o que nos remete diretamente ao capítulo final do romance. Assim sendo, o delírio aqui descrito parece estar construído de forma a parodiar o que postulamos como delírio místico, o que nos permite colocar os delírios de Machado e Flaubert em extremos opostos quanto ao tratamento temático: um predominantemente laico e o outro predominantemente marcado pela religiosidade mística.

Por fazer uso de postulados da psicanálise, nosso percurso de análise mostrou a existência de estruturas peculiares nas descrições dos delírios, as quais remetem a estruturas tidas pelo discurso psicanalítico como propiciadores de alucinações. Contudo, como

\footnotetext{
${ }^{9}$ Lacan aborda essa questão em “De uma questão preliminar a todo tratamento possível para a psicose” (1966).

${ }^{10}$ O Nome-do-Pai seria para Lacan uma estrutura advinda do terceiro elemento da tríade Edípica, ou seja, do lugar que é associado ao lugar do pai, uma vez que este se caracteriza por sua posição ativa e por seu papel de detentor da Lei, ou seja, das regras e imposições próprias da sociedade.
} 
compreender essa relação entre literatura e psicanálise sem cair no anacronismo ${ }^{11}$ que se torna evidente se levarmos em consideração a posterioridade desses postulados da psicanálise com relação à época de produção dos romances analisados? Talvez essa questão seja mais bem compreendida se pensarmos numa relação entre literatura e psicanálise mais ampla, que não se resuma a um instrumento de análise do crítico literário sem levar em conta o processo de constituição das duas áreas enquanto discursos.

Para tanto, devemos aqui lembrar que a psicanálise, que começava a despontar como ciência, ainda de forma bastante incipiente, na segunda metade no século XIX, já se fazia presente enquanto um discurso de elevado interesse, o que se traduz na forte presença de temas como o alienismo, por exemplo, na literatura. Em nosso caso, é interessante observar a forte recorrência de alucinações na obra de Flaubert - onde essa presença se faz perceber de forma mais patente - e na de Machado, o que nos permite afirmar que os dois autores, como homens do seu tempo, já estavam em contato com esse discurso inicial que viria a se constituir como a ciência psicanalítica.

É possível afirmar que o simples interesse dos autores acerca desses "fenômenos mentais" - para utilizar as palavras do próprio Brás Cubas ${ }^{12}$ - e sua inclusão nas obras ainda não nos permite dizer que há uma representação estrutural de mecanismos psicanalíticos desencadeadores da alucinação nos delírios estudados, uma vez que esses mecanismos ainda não haviam sido observados e postulados como tal pela psicanálise. Não podemos, da mesma forma, admitir que o que constatamos em nossa análise seja resultado de uma mera coincidência, sobretudo se tivermos em mente o fato de a psicanálise ter feito e fazer um conhecido uso da literatura, tanto para a observação e constatação de seus postulados, quanto para a ilustração de suas teorias. Essa questão, cerne das relações entre literatura e psicanálise desde Freud, não escapa aos estudiosos que se dedicam ao tema, como podemos contemplar na obra de Assoun:

Il s'agit de comprendre de façon vivante comment la psychanalyse, au moment même où elle définit son propre champ, son objet et sa méthode étude des processus psychiques dits inconscients, à partir des acquis d'une méthode de traitement des troubles névrotiques - rencontre la question de la littérature ou plus précisément de la création littéraire.

(...)

Il convient donc de souligner la problématique originaire dans laquelle la question psychanalyse et littérature a été formulée, chez Freud même.

On pourrait dire que c'est moins le texte lui-même que le processus de création d'une part, l'effet produit par cette création sur le lecteur d'autre part, qui intéresse Freud. (1996, p. 4)

Diante disso, vemos que desde os primórdios da psicanálise, em seus estudos freudianos iniciais, a literatura era não apenas um campo de interesse, mas um campo com o qual se estabelecia um diálogo intenso, fazendo com que esta se tornasse um objeto de estudo

\footnotetext{
${ }^{11} \mathrm{O}$ anacronismo evidente com relação à abordagem literária de temas da ordem do psiquismo humano também foi observado, de certa forma, por Candido em um artigo que trata da aproximação entre Machado e Xavier de Maistre: “A 'alma' e o 'outro' podem assim atuar como se fossem independentes, mantendo relação caprichosa, ilustrada por acidentes e distrações que vão parecendo tão significativos e próprios do ser quanto os atos conscientes, como se Xavier de Maistre estivesse inaugurando, mais de um século antes de Freud, algo parecido ao que este chamaria 'psicopatologia da vida quotidiana', baseada na análise dos lapsos" (CANDIDO, 1989, p.103).

12 “Que me conste, ainda ninguém relatou o seu próprio delírio; faço-o eu, e a ciência mo agradecerá. Se o leitor não é dado à contemplação dêstes fenômenos mentais, pode saltar o capítulo; vá direto à narração" - grifos nossos. (ASSIS, 1881, p.119)
} 
quando Freud passa a se voltar para a questão da criação literária e do efeito da obra de arte, anunciando aí possíveis campos de estudos que se desenvolveriam bem posteriormente com a crítica genética e com a estética da recepção, respectivamente.

A psicanálise, ao que nos parece, ao fazer uso da literatura no seu processo de constituição como ciência, deixa claro uma intrínseca relação discursiva entre os dois campos, relação que se mostra numa via de mão dupla, já que a literatura também se nutriu de discursos e de temas concernentes à psicologia que antecederam à consolidação da psicanálise e, posteriormente, de discursos da própria psicanálise já constituída ${ }^{13}$.

Para compreender a relação entre literatura e psicanálise deve-se levar em conta uma relação discursiva que prevê uma permeabilidade de discursos ${ }^{14}$, no que tange principalmente à literatura ${ }^{15}$, que se nutre de discursos de vários campos ao longo do processo de construção literária.

No entanto, se colocarmos a questão da relação entre discursos no cerne da criação literária, estaremos colocando em xeque o aspecto mimético da literatura, uma vez que esta, segundo nosso ponto de vista, se constitui não a partir de uma relação com um possível referente do mundo externo, mas a partir de um dialogismo discursivo - tanto numa relação entre obras literárias quanto entre diversos campos do saber. A problemática concernente à mímesis nos toca ainda mais de perto se observarmos a estrutura dos delírios aqui estudados, uma vez que estes são construídos primordialmente a partir de trechos descritivos. Vale a pena, então, observar essas descrições ${ }^{16}$.

\section{Comparar Flaubert e Machado a partir da estrutura: observando a DESCRIÇÃO}

Os delírios presentes nas obras de Flaubert e Machado, conforme pudemos contemplar na primeira parte desse artigo, são construídos de forma a colocar em primeiro plano as visões alucinatórias das personagens, o que é feito através da inserção de trechos descritivos no fio da narrativa: as descrições do delírio-procissão no caso de Flaubert e as descrições da personagem Pandora e do espetáculo do desfilar dos séculos no caso de Machado. Dessa forma, temos em ambas as descrições uma representação de imagens exteriores problematizadas pelo foco narrativo e por sua inserção no processo alucinatório das personagens: com o foco narrativo em Félicité, a descrição da procissão externa se torna descrição de seus delírios, o que ocorre de forma patente no caso de Brás Cubas, onde a

\footnotetext{
${ }^{13}$ Essa relação recíproca entre literatura e psicanálise foi analisada por Verónica Galíndez Jorge (2003), com especial enfoque para a observação da circulação do discurso médico no século XIX e sua apropriação pela escritura flaubertiana, no que concerne à alucinação.

${ }^{14}$ Utilizamos aqui o termo "permeabilidade discursiva" cunhado por Rigoli (2001), obra à qual reenviamos nosso leitor. No que respeita à relação discursiva de que vimos tratando, esta será abordada de maneira mais teórica na terceira parte do presente artigo.

${ }^{15}$ Essa mesma permeabilidade discursiva foi igualmente observada por Assoun, no que respeita à psicanálise "La psychanalyse passe pour une fatalité qui somme tous les savoirs et toutes les pratiques de la signification de s'y confronter : le savoir de l'inconscient ne laisse pas indemne le rapport du discours lui-même." (1996, p. 3) -, aspecto no qual, no entanto, não nos deteremos, uma vez que nosso interesse aqui é literário e não psicanalítico.

${ }^{16}$ A análise da descrição em Flaubert e Machado, no que respeita à mímesis e à teoria barthesiana da escritura, foi por nós empreendida num artigo publicado e apresentado no IX Congresso da Associação de Pesquisadores em Crítica Genética, no dia 24 de novembro de 2008, ao qual reenviamos, uma vez que faremos aqui uma exposição menos detida acerca desse assunto, levantando apenas os pontos que nos interessam em nosso objetivo geral (SCHOEPS, 2008).
} 
narração segue em primeira pessoa. Há em ambos os casos um processo de subjetivação, visto haver um afastamento com relação ao que seria um discurso objetivo de um narrador totalmente onisciente, através da tomada de posição do ponto de vista das personagens. Poderse-ia dizer que, mesmo sendo representantes do foco de observação das personagens, as descrições apresentadas não perderiam seu caráter mimético, ou seja, continuam a representar algo. Contudo, se observarmos o modo segundo o qual as descrições são construídas, veremos que essa representatividade é de alguma forma inviabilizada.

No caso flaubertiano, analisaremos aqui um pequeno trecho no qual é descrito o altar da procissão que ocorre enquanto a personagem delira em seu leito de morte:

Des guirlandes vertes pendaient sur l'autel, orné d'un falbalas en point d'Angleterre. Il y avait au milieu un petit cadre enfermant des reliques, deux orangers dans les angles, et, tout le long, des flambeaux d'argent et des vases en porcelaine, d'où s'élançaient des tournesols, des lis, des pivoines, des digitales, des touffes d'hortensias. Ce monceau de couleurs éclatantes descendait obliquement, $d u$ premier étage jusqu'au tapis se prolongeant sur les pavés; et des choses rares tiraient les yeux. Un sucrier de vermeil avait une couronne de violettes, des pendeloques en pierres d'Alençon brillaient sur de la mousse, deux écrans chinois montraient leurs paysages. Loulou, caché sous des roses, ne laissait voir que son front bleu, pareil à une plaque de lapis. (FLAUBERT, 1877, p. 63, grifos nossos)

Vemos que no quadro descrito há uma profusão de detalhes do altar, dando-nos a impressão de que a descrição abarca a totalidade do objeto. Cooperando para essa impressão de uma descrição bem sucedida, percebemos uma insistência em determinar com exatidão o espaço de cada detalhe, através do uso quase que exagerado de marcadores espaciais tais como sur, au milieu de, dans les angles, tout le long, où, sous etc. Assim sendo, percebemos que há um esforço enorme em preencher todo o espaço a ser descrito, como numa busca de reproduzir fielmente o real. No entanto, se tentarmos reproduzir pictoricamente essa descrição, veremos que ela não chega a construir objeto algum, apesar de nos dar inúmeros elementos para tanto.

Se observarmos melhor o trecho da descrição, veremos que se baseia em algo que, apesar de bem marcado espacialmente, se assemelha mais a uma enumeração ou a uma lista de detalhes: "Il y avait au milieu un petit cadre enfermant des reliques, deux orangers dans les angles, et, tout le long, des flambeaux d'argent et des vases en porcelaine, d'où s'élançaient des tournesols, des lis, des pivoines, des digitales, des touffes d'hortensias". Além disso, a descrição não segue um movimento tradicional, indo do todo às partes, ou seja, começando pela totalidade do objeto para em seguida mostrar os detalhes deste, uma vez que não temos nenhuma informação prévia acerca do altar enquanto objeto em si, tal como seu formato geral ou suas dimensões, mas uma incursão direta num detalhe: Des guirlandes vertes pendaient sur l'autel. Dessa forma, somos, enquanto leitores, obrigados a localizar espacialmente os detalhes dessa descrição num objeto para nós desconhecido. É claro que todo leitor tem em si alguma representação do que seja um altar, o que talvez dispensaria o narrador de descrevê-lo em minúcias; no entanto, esse jogo da descrição permite que cada um imagine um altar diferente, o que inviabiliza a construção de um objeto unívoco e problematiza a representação do real. Percebemos, então, que a descrição não se preocupa aqui em 'desenhar' esse altar, mas apenas em preenchê-lo com detalhes.

A descrição segue nessa profusão de detalhes que nos são agora apresentados de forma ainda mais problemática, pois as partes descritas não são sequer nomeadas, mas caracterizadas de forma abstrata: Ce monceau de couleurs éclatantes e des choses rares. Assim, apesar de as expressões se referirem, respectivamente, ao que foi dito anteriormente e 
ao que será enumerado logo em seguida, o leitor novamente é solicitado a imaginar o que vem a ser um monte de cores irradiantes e coisas raras, expressões que resumem, de certa forma, o que está sendo descrito e trazem à descrição uma idéia de indefinição, como se o objeto estivesse envolto numa névoa que não permitisse a separação desses detalhes arbitrários. É interessante notar que é justamente essa a impressão que nos fica: a profusão de detalhes não constrói um objeto, mas 'ofusca' a visão do observador, que não mais distingue um objeto em meio aos elementos enumerados. Isso porque a descrição detalhista de Flaubert, ao operar essa enumeração de objetos acaba por justapô-los num mesmo espaço a ser preenchido, 'empilhando-os', numa descrição que vários críticos chamaram de 'piramidal'.

Ao final da descrição, percebemos que esta, apesar das inúmeras minúcias que nos fornece, não nos informa nada de relevante, pois se prende em objetos pouco importantes e até mesmo inusitados como as 'coisas raras' do altar: Un sucrier de vermeil avait une couronne de violettes, des pendeloques en pierres d'Alençon brillaient sur de la mousse, deux écrans chinois montraient leurs paysages. Assim, a descrição, enquanto discurso, é algo bem construído e estruturado, mas seu referente permanece indefinido e cambiante.

Já no caso machadiano, a descrição também aparece de forma problematizada, como podemos perceber no seguinte trecho do delírio, no qual a personagem Pandora é descrita:

Caiu do ar? destacou-se da terra? não sei; sei que um vulto imenso, uma figura de mulher me apareceu então, fitando-me com uns olhos rutilantes como o sol. Tudo nessa figura tinha a vastidão das formas selváticas, e tudo escapava à compreensão do olhar humano, porque os contornos perdiam-se no ambiente, e o que parecia espêsso era muita vez diáfano. Estupefacto, não disse nada, não cheguei sequer a soltar um grito; mas, ao cabo de algum tempo, que foi breve, perguntei quem era e como se chamava: curiosidade de delírio.

(...)

Dizendo isto, a visão estendeu o braço, segurou-me pelos cabelos e levantou-me ao ar, como se fôra uma pluma. Só então, pude ver-lhe de perto o rosto, que era enorme. Nada mais quieto; nenhuma contorção violenta, nenhuma expressão de ódio ou ferocidade; a feição única, geral, completa, era a da impassibilidade egoísta, a da eterna surdez, a da vontade imóvel. Raivas, se as tinha, ficavam encerradas no coração. Ao mesmo tempo, nesse rosto de expressão glacial, havia um ar de juventude, mescla de força e viço, deante do qual me sentia eu o mais débil e decrépito dos sêres. (ASSIS, 1881 , p.121-2, grifos nossos)

A descrição da personagem Pandora, como podemos observar, pretende dar conta das características físicas da personagem, o que nos levaria a imaginar que a descrição nos fornecerá um retrato objetivo desta. No entanto, percebemos que, apesar de haver uma descrição total da personagem, mostrando sua aparência geral - o todo - e, em seguida, seus detalhes - as partes -, o que é exposto são apenas traços abstratos e genéricos como um vulto imenso e uma figura de mulher. O leitor é também convocado a criar para si imagens do que é dito, gerando 'desenhos' diversos para cada leitor.

A convocação ao leitor se torna ainda mais expressiva quando o narrador, em vez de nos dar as dimensões da personagem, diz que ela possui a vastidão das formas selváticas, entrando em campos de comparações mais inusitados que os anteriores. Ademais, com a inclusão de comparações, a descrição caminha para uma subjetividade cada vez mais acentuada, deixando para o leitor a função de construir imageticamente o objeto e fazendo com que a descrição seja tão ou mais cambiante quanto a própria personagem, cujos contornos perdem-se no ambiente, uma vez que o que parecia espêsso era muita vez diáfano. 
Entrando na descrição das partes da personagem, esta não é menos indefinida, já que o rosto de Pandora é apenas caracterizado como enorme, sem que se definam suas proporções. A descrição, então, passa para um movimento de interiorização, buscando caracterizar o exterior desse rosto sem expressões por traços abstratos de sentimentos internos: a feição única, geral, completa, era a da impassibilidade egoísta, a da eterna surdez, a da vontade imóvel (...), nesse rosto de expressão glacial, havia um ar de juventude, mescla de força e viço. Para vislumbrar a imagem de Pandora o leitor tem que imaginar o que seja uma impassibilidade egoísta ou um ar de juventude, imagens que, por mais que possam ter uma determinada representação estereotipada - caso da juventude mesclando força e viço - não são concretas e não dependem inteiramente da descrição para serem construídas. Seria interessante observar que é a escolha dos adjetivos e dos substantivos nesse trecho que contribui para esse efeito, visto haver sempre uma conjugação de algo mais abstrato com algo mais concreto - impassibilidade egoísta, eterna surdez, vontade imóvel -, o que causa um certo estranhamento e dificulta a formação de uma imagem pictural.

A descrição nos dá dados para a construção de imagens, sem as construir por completo, num movimento de inclusão do leitor nesse processo de construção imagética. Isso afasta a descrição de uma objetividade pretendida numa representação fiel do real, fazendo com que ela seja predominantemente subjetiva, visto que a construção das imagens se concretizará no leitor, não havendo a construção de objetos, mas de um discurso descritivo. Essa descrição acaba por revelar a impossibilidade de descrever um objeto, ou seja, de representá-lo através da mediação da linguagem.

Percebemos, além de uma impossibilidade em descrever, uma perda da função da descrição. Sobre esse assunto, Gérard Genette (1969), buscando o que no discurso literário faz fronteira à narração, observa que a descrição possui, ao menos, duas grandes funções no que tange à economia geral da obra, segundo a tradição clássica: a primeira contempla a descrição como uma figura de estilo, como um elemento decorativo da narração que aparece numa espécie de nicho, constituindo "une pause et une récréation dans le récit" (1969, p. 58); a segunda a contempla como um espaço onde o narrador informa e explica os elementos da narração, o que traz à descrição um caráter simbólico, como em Balzac, por exemplo, onde as descrições "tendent (...) à révéler et en même temps à justifier la psychologie des personnages" (1969, p. 59), numa espécie de determinismo um tanto redutor. De toda forma, a descrição aqui possui alguma função, mesmo se ela às vezes é subjugada à narração, executando um papel passivo no todo da obra ${ }^{17}$.

Esse tipo de descrição, segundo Genette, vai ser aos poucos substituído por uma descrição mais ornamental, sobretudo no começo do século XX, o que, apesar de seu grande desenvolvimento na obra, vai acarretar na perda de sua autonomia com relação à narração: mesmo no chamado Nouveau Roman, a descrição serve para contar uma história, ou seja, ela adquire uma função puramente narrativa, uma vez que "la description est tout naturellement ancilla narrationis, esclave toujours nécessaire, mais toujours soumise, jamais émancipée" $\left(1969\right.$, p.57) ${ }^{18}$.

As descrições aqui estudadas, tanto por não serem capazes de construir um objeto como por se centrarem em detalhes sem importância, não mais apresentam um caráter

\footnotetext{
${ }^{17}$ Essa passividade da descrição é, aliás, sublinhada por Genette como uma característica da literatura clássica: "Il ne semble pas, à première vue, qu'elle [la description] ait une existence très active avant le XIX ${ }^{\mathrm{e}}$ siècle, où l'introduction de longs passages descriptifs dans un genre typiquement narratif comme le roman met en évidence les ressources et les exigences du procédé " (1969, p.56).

${ }^{18}$ Nesse sentido, Genette afirma que a descrição apresenta um duplo comportamento: ela é mais indispensável que a narração, pois é mais fácil descrever sem narrar do que narrar sem descrever, mas, no entanto, não existe um gênero literário puramente descritivo, ou seja, a descrição aparece sempre subjugada ao gênero narrativo, onde ela tem um papel secundário.
} 
informativo, aproximando-se mais, talvez, a uma espécie de descrição ornamental. No entanto, não nos parece que as descrições aqui analisadas sejam uma pausa recreativa da narração, o que nos leva a pensá-las como algo que apenas preenche uma formalidade do discurso romanesco, o qual exige a presença de discursos descritivos nos romances.

Dessa forma, as descrições presentes nas obras passam a adquirir um caráter que as afasta de uma relação puramente mimética com o real para colocar em relevo a estrutura da obra e o próprio sistema literário: o leitor, ao perceber uma descrição que não descreve, vai justamente se questionar acerca da funcionalidade de uma descrição por assim dizer vazia, percebendo que ela é apenas uma formalidade do sistema literário. Assim, a literatura acaba por sublinhar sua própria estrutura, mostrando-se como algo artificial e, portanto, ficcional, adquirindo uma postura auto-reflexiva própria do que Roland Barthes (1953) chamou de escritura.

\section{COMPARAR Flaubert E MACHADO: DECORRÊNCIAS TEÓRICAS}

Como vimos, nosso percurso de análise, no que concerne tanto às relações entre literatura e psicanálise quanto à questão da mímesis, nos levou a um questionamento do próprio sistema literário: visto, na primeira parte, dentro de uma relação entre discursos e, na segunda parte, numa posição auto-reflexiva. Podemos observar, dessa forma, que nosso projeto inicial de comparar Flaubert e Machado caminhou para além de uma simples comparação entre as obras dos dois autores, abrindo caminho para refletirmos sobre a literatura em si e sobre o próprio fazer literário. Isso porque uma literatura que se faz na relação entre discursos vários e coloca em pauta seu próprio processo de construção - ao tornar-se auto-reflexiva e, portanto, auto-referencial - nos faz contemplar o próprio processo pelo qual a literatura se constitui como discurso.

Apesar de abrir nosso campo de reflexão, chegando a questões que são válidas para toda a literatura - e não somente para Machado e Flaubert - e que tocam em pontos fundamentais da própria teoria literária, podemos também tentar nos afastar dessa difusão e operar um fechamento de nosso campo óptico, visando retornar para nosso objeto inicial de estudo: a obra dos dois grandes nomes da literatura francesa e brasileira, Gustave Flaubert e Machado de Assis.

Nossa pesquisa, tentando encontrar meios de aproximar dois autores cujas relações não se fazem de forma explícita - o que não nos permitiu fazer uso das teorias correntes da literatura comparada - , seguiu numa análise das obras dos escritores, sempre empreendida ao lado e à luz de postulados teóricos que balizassem nosso estudo e que nos permitissem estabelecer um diálogo entre as obras. Como expusemos acima, um importante aspecto do sistema literário se fez presente em nossas reflexões, apontando para a auto-referencialidade da literatura e para uma relação que se estabelece entre discursos. Faz-se necessário, nesse ponto, explicitar de que forma estamos contemplando essa relação discursiva.

Michel Foucault, em sua Archéologie du savoir (1969), indica uma nova abordagem para as relações a serem estabelecidas entre discursos. Num viés estruturalista, o autor coloca os discursos em relação dentro de uma rede associativa, na qual cada elemento adquire significação por oposição aos outros membros da rede, numa dinâmica semelhante ao sistema de valor saussuriano, exposto em seu Cours de lingüistique générale (1916). É interessante notar, no entanto, que essa rede de associações se dá através do que Foucault chamou de dispersão discursiva, ao propor que cada discurso da rede reenvia a outros discursos, operando uma difusão. Assim sendo, o sistema literário pode ser encarado dentro dessa rede discursiva, na qual um livro só obtém significação dentro de um processo de retro-alimentação literária, onde discursos diversos dialogam entre si para formar o amálgama discursivo que é a 
literatura. Assim sendo, constrói-se um campo literário ${ }^{19}$ no qual cabem discursos de diversas áreas do saber, seja a psicanálise, a sociologia, a filosofia ou até mesmo as ciências exatas.

É nesse ponto que reencontramos nossos escritores, uma vez que os postulados teóricos aqui propostos nos permitem compreender não somente as questões que suscitamos, como a relação entre literatura e psicanálise nas obras estudadas, mas também a problemática comparação entre Flaubert e Machado, já que a via usual de seguir as citações explícitas do autor brasileiro, para se chegar às suas fontes na literatura francesa, é inviabilizada.

Nossa postura crítica nos permite construir uma rede de relações na qual Gustave Flaubert e Machado de Assis fazem parte de um mesmo campo literário, o qual entrevê o sistema literário dentro de um fazer que pressupõe o diálogo com outros discursos, decorrentes de um processo de forte erudição - processo que se torna evidente se pensarmos na grande quantidade de citações explícitas e implícitas que Machado inclui em suas obras e no não menor número de obras consultadas por Flaubert para a composição de suas obras.

Esses autores colocam-se como artesãos da escritura ${ }^{20}$, admitindo um fazer que inclui de forma intrínseca o trabalho escritural e prevê uma posição de autocrítica da linguagem e da literatura, transformando-a, pela primeira vez, em um objeto da própria literatura. Nascidos no seio de literaturas românticas - que, ademais, os formaram enquanto escritores -, nossos autores souberam, dessa forma, romper com a tradição e inaugurar uma literatura à frente do seu tempo, dando vazão ao que seria o germe da modernidade literária, ao permitir a pluralidade de escrituras e ao questionar a literatura em sua própria essência:

Chaque fois que l'écrivain trace un complexe de mots, c'est l'existence même de la Littérature qui est mise en question; ce que la modernité donne à lire dans la pluralité de ses écritures, c'est l'impasse de sa propre Histoire. (BARTHES, 1953, p. 49) c $^{\text {d }}$

Agradecimentos: À Fapesp, pela bolsa concedida, e à Verónica, pela orientação e pelos comentários e intervenções sempre motivadores.

\footnotetext{
${ }^{19}$ Fazemos aqui alusão direta aos postulados de Bourdieu, presentes em Les règles de l'art (1992).

${ }^{20}$ Com a denominação "artesãos da escritura" fazemos referência ao texto de Barthes "L'artisanat du style" (1953), ao qual reenviamos.
} 


\section{REFERÊNCIAS BIBLIOGRÁFICAS:}

ASSIS, M. de. Memórias Póstumas de Brás Cubas. Rio de Janeiro: INL; MEC, 1960 [1881].

ASSOUN, P. L. Littérature et psychanalyse. Freud et la création littéraire. Paris: Ellipses, 1996.

BARBOSA, J. A. "Volúpia lasciva do nada: uma leitura de 'Memórias póstumas de Brás Cubas"”. Revista USP. São Paulo, no 1, p.107-120, mar/mai, 1989.

BARTHES, R. Le degré zéro de l'écriture, suivi de Nouveaux essais critiques. Paris: Seuil, 2004 [1953, 1972].

BOURDIEU, P. Les règles de l'art: genèse et structure du champ littéraire. Paris: Seuil, 1998 [1992].

CANDIDO, A. "À roda do quarto e da vida". Revista USP. São Paulo, no 2, p.101-104, jun/ago, 1989.

FLAUBERT, G. “Un cœur simple”. Trois contes. Paris: Louis Conard, 1910 [1877].

FOUCAULT, M. L'archéologie du savoir. Paris : Gallimard, 1969.

GENETTE, G. "Frontières du récit". Figures II. Paris: Seuil, 1969, p.49-69. "Les silences de Flaubert". Figures. Paris: Seuil, 1962, p.223-243.

GREVISSE, M. Le bon usage. Gembloux: Éditions J. Duculot, 1964.

JORGE, V. G. Como as mil peças de um jogo de escritura nos manuscritos de Flaubert. 2003. Tese de doutorado, Universidade de São Paulo, São Paulo, defendida em 19 de dezembro de 2003. (Inédita)

LACAN, J. "De uma questão preliminar a todo tratamento possível para a psicose". Escritos. Trad. Vera Ribeiro. Rio de Janeiro: Jorge Zahar Editora, 1998 [1966], p.537-590.

O Seminário: livro XX. Mais, ainda. Trad. M. D. Magno. Rio de Janeiro: Jorge Zahar Editora, 1985 [1975].

RIGOLI, J. Lire le délire. Aliénisme, rhétorique et littérature en France au XIX ${ }^{e}$ siècle. Paris: Fayard, 2001.

ROUSSET, J. "Madame Bovary ou le livre sur rien". Forme et signification. Essais sur les structures littéraires de Corneille à Claudel. Paris: José Corti, 1962, p.109- 133.

SAUSSURE, F. Curso de lingüística geral. São Paulo: Cultrix, 1969 [1916].

SCHOEPS, L. A. "Alucinações de morte na obra de Flaubert e Machado: o gozo místico e o delírio laico". In: CIRILLO, J. et GRANDO, A. (orgs.). Processo de criação e interações: a crítica genética em debate nas artes, ensino e literatura. Belo Horizonte: C/Arte, 2008, vol. 2, p. 194-200.

SCHREBER, D. Memórias de um doente dos nervos. Trad. Marlene Caroni. Rio de Janeiro: Edições Graal, 1984 [1903].

WILLEMART, P. Além da psicanálise: a literatura e as artes. São Paulo: Nova Alexandria; FAPESP, 1995. 